\title{
Redescription of Nothobranchius lucius and description of a new species from Mafia Island, eastern Tanzania (Cyprinodontiformes,Aplocheilidae)
}

\author{
Wilson J. E. M. Costa ${ }^{1}$ \\ 1 Laboratory of Systematics and Evolution of Teleost Fishes, Institute of Biology, Federal University of Rio de Janeiro, Caixa Postal 68049, CEP \\ 21941-971, Rio de Janeiro, Brazil
}

http://zoobank.org/5E935371-57D2-4D44-A003-A61F40B54A85

Corresponding author: Wilson J. E. M. Costa (wcosta@acd.ufrj.br)

\begin{abstract}
Received 3 November 2016

Accepted 10 January 2017

Published 16 January 2017

Academic editor:

Peter Bartsch

\section{Key Words}

Biodiversity hotspot

East African coastal forests

Nothobranchius melanospilus species group

Rufiji River

systematics

taxonomy

Examination of specimens listed in the original description of Nothobranchius lucius revealed that they belong to two species. Nothobranchius lucius is redescribed based on the type series and other specimens collected in the type locality area, the Kibasira Swamp area, Rufiji River basin, Tanzania, at elevations between 250 and $300 \mathrm{~m}$. Nothobranchius insularis sp. n. is described on the basis of specimens collected in the north part of Mafia Island, Tanzania, at about 10-15 m elevation. Nothobranchius lucius and N. insularis are considered closely related species based on the shared presence of long jaws; caudal fin, in males, with a broad dark grey to black band on its posterior margin; black dots over the whole flank, in females; metapterygoid curved, with its middle and dorsal portions separated from the sympletic by a broad interspace; and posterior process of the quadrate shorter than the ventral length of the quadrate without process. Characters useful to distinguish them include premaxillary dentition, caudal fin shape, colour pattern of flank and unpaired fins in females, fin length, and number of neuromasts of the posterior section of the anterior supraorbital series. Both species are members of a group that also includes $N$. elongatus, $N$. hengstleri, $N$. interruptus, $N$. jubbi, $N$. krammeri, and N. melanospilus, which are all diagnosed by the presence of two neuromasts in the anterior section of the anterior supraorbital series.
\end{abstract}

\section{Introduction}

The East Africa region comprising the coastal forests of south-eastern Kenya and eastern Tanzania is an important centre of biological diversity often known as the East Africa biodiversity hotspot (EABH), with high occurrence of endemic species (Myers et al. 2000, Azeria et al. 2007). This region exhibits the greatest species diversity of Nothobranchius Peters, 1868, a killifish genus that occurs in a wide geographical portion of central and eastern Africa (e.g., Parenti 1981). Among the about 60 valid species in the genus, 27 have been recorded in EABH (e.g., Costa 2009, Dorn et al. 2014). Species of Nothobranchius live in temporary pools formed during the rainy season, where resistant eggs undergo diapause during the dry season (e.g., Polacik et al. 2011, Pin- ceel et al. 2015). In EABH, there are two rainy seasons, the 'long rains' (Masika), from March to May, and the 'short rains' (Muli), from October to December, which alternate with dry periods when pools and some streams completely disappear, as described first by Fitzgerald (1898). Species of Nothobranchius and other African and South American aplocheiloid killifishes possessing this uncommon life cycle have been equivocally called annual fishes, reflecting the past belief that these fishes have a single generation per year (e.g., Myers 1942). Aplocheiloid killifishes with this life cycle have been alternatively known as seasonal killifishes in more recent studies (e.g., Costa 2002).

Species of Nothobranchius have been recently proposed as model organisms for ageing processes since they are naturally short-lived and easily bred in laboratories 
(e.g., Genade et al. 2005, Harel et al. 2015). However, they are mainly known as aquarium fishes due to the striking colouration exhibited by males of most species in the genus. Consequently, in the last four decades many collecting trips in $\mathrm{EABH}$ have been reported in the aquarium fish literature (e.g., Seegers 1997, Wildekamp 2004; Neumann 2008), which resulted in several new taxonomic records and descriptions of new species.

In a brief revision of the $N$. melanospilus species group, Wildekamp et al. (2009) described N. lucius Wildekamp, Shidlovskiy \& Watters, 2009 on the basis of material collected in the Kilombero River drainage, Tanzania, which had been formerly identified as $N$. aff. melanospilus in the aquarium fish literature (e.g., Wildekamp 2004). In the original description of $N$. lucius, specimens from the Mafia Island, in Tanzania, previously identified as N. melanospilus (Pfeffer 1896) by Wildekamp (2004), were listed as additional non-type material belonging to $N$. lucius. The N. melanospilus species group was tentatively diagnosed by the presence of dark dots on the flank in females (i.e., black in N. melanospilus, dark brown in $N$. lucius and pale grey in N. makondorum Wildekamp, Shidlovskiy \& Watters, 2009, according to Wildekamp et al. 2009). Subsequently, monophyly of this species group was supported in a multigene phylogeny (Dorn et al. 2014). All specimens listed by Wildekamp et al. (2009) is deposited in the Muséé Royal de l'Afrique Centrale (MRAC), Tervuren, Belgium.

While studying aplocheilid collections deposited in MRAC, discrepancies were found between data obtained by the current author from that listed by Wildekamp et al. (2009) from the same specimens. Consequently, a redescription of $N$. lucius is warranted and presented here. Comparisons also indicated that the populations from the Mafia Island, an off-shore island in the coast-line of Tanzania, belong to a distinct, new species, which is herein described.

\section{Methods}

All material examined is deposited in Musée Royal de l'Afrique Central, Tervuren (MRAC). Morphometric and meristic data were taken following Costa (1988), except for the snout length, measured between the anterior margin of the orbit and the anterior extremity of the middle portion of the upper jaw; measurements are presented as percent of standard length (SL), except for those related to head morphology, which are expressed as percent of head length. Specimens with deformed body were not measured to avoid unnecessary error. Fin-ray counts include all elements. Osteological preparations (C\&S) were made according to Taylor and Van Dyke (1985). Terminology for frontal squamation follows Hoedeman (1958) and for cephalic neuromast series Costa (2001). Species were delimited using unique combinations of character states (diagnosability criterion; e.g., Davis and Nixon 1992).

\section{Results}

Nothobranchius lucius Wildekamp, Shidlovskiy \& Watters, 2009

Fig. 1, Table 1

Nothobranchius lucius Wildekamp, Shidlovskiy \& Watters, 2009: 247 (holotype: MRAC A7-02-P-9, $49.6 \mathrm{~mm} \mathrm{SL}$; type locality: large pool on west side of road between Ifakara and the Kilombero River ferry, $2 \mathrm{~km}$ south of Ifakara, $1 \mathrm{~km}$ north of the Kilombero River, Tanzania, $8^{\circ} 10.30^{\prime}$ 'S $\left.36^{\circ} 41.54^{\prime} \mathrm{E}\right)$.

Material examined. MRAC A7-02-P-9, holotype; MRAC A7-02-P-10-25, 16 paratypes (1 C\&S); Tanzania: pool on west side of the road between Ifakara and the Kilombero River ferry, $2 \mathrm{~km}$ south of Ifakara, $1 \mathrm{~km}$ north of the Kilombero River, $8^{\circ} 10.30^{\prime} \mathrm{S} 36^{\circ} 41.54^{\prime} \mathrm{E}$, about $250 \mathrm{~m}$ asl; B. Watters et al., 10 Jun. 2000. - MRAC 98-008-P-0007-0012, 6 paratypes; Tanzania: $2 \mathrm{~km}$ south of Ifakara, on east side of the road to Kilombero River ferry, northernmost pool between village and ferry; $8^{\circ} 10.04^{\prime} \mathrm{S} 36^{\circ} 41.61^{\prime} \mathrm{E}$, about $250 \mathrm{~m}$ asl; B. Watters et al., 7 Jun. 1995. - MRAC A7-02-P-26-27, 2; Tanzania: $1 \mathrm{~km}$ south of Minepa village, large circular pool on west side of Ifakara-Lupiro road, $17 \mathrm{~km}$ south of Ifakara; $8^{\circ} 16.34^{\prime} \mathrm{S} 36^{\circ} 40.83^{\prime} \mathrm{E}$, about $270 \mathrm{~m}$ asl; B. Watters et al., 11 Jun. 2000. - MRAC A7-02-P-28-32, 5; Tanzania: 2 $\mathrm{km}$ southwest of Lupiro on road to Malinyi, $27 \mathrm{~km}$ south of Kilombero River ferry, ditch on southeast side of road; $8^{\circ} 23.45^{\prime} \mathrm{S} 36^{\circ} 39.45^{\prime} \mathrm{E}$, about $300 \mathrm{~m}$ asl; B. Watters et al., 11-12 Jun. 2000. - MRAC A7-02-P-37, 1; Tanzania: small pool at culvert on southeast side of Ifakara-Ruipa road, $37 \mathrm{~km}$ west of Ifakara, $0.5 \mathrm{~km}$ northeast of the junction to Narubungo village, on northern flanks of Kibasira Swamp; $8^{\circ} 08.88^{\prime} \mathrm{S} 36^{\circ} 24.91^{\prime} \mathrm{E}$, about $280 \mathrm{~m}$ asl; B. Watters et al., 9 Jun. 2002.

Diagnosis. Nothobranchius lucius differs from all other species of the $N$. melanospilus group, except $N$. insularis, by having snout pointed in lateral view, jaws moderately long (vs. snout blunt to weakly pointed, jaws short); caudal fin, in males, with broad dark grey to black band on the posterior margin (vs. narrow); presence, in females, of dark dots over the whole flank (dark dots when present restricted to the posterior portion of the flank). It is distinguished from $N$. insularis by having inner premaxillary teeth larger than teeth of the outer premaxillary tooth row (vs. smaller); caudal fin rounded in males (vs. subtruncate); in females, flank dark dots are rounded and arranged in horizontal rows (vs. dots vertically elongated, often arranged in oblique rows); unpaired fins, in females, with dark grey dots extending over most fin (dots restricted to the basal portion of unpaired fins); caudal, pectoral and pelvic fins longer (caudal fin length in males 31.3$34.9 \% \mathrm{SL}$ and $30.3-32.9 \% \mathrm{SL}$ in females of $N$. lucius, vs. $26.9-29.6 \%$ SL in males and $22.8-27.4 \%$ SL in females of $N$. insularis; pectoral-fin length $22.2-24.5 \% \mathrm{SL}$ in males and 20.2-24.6\% SL in females, vs. 17.1-21.8 $\%$ SL and 14.2-19.3\% SL, respectively; pelvic-fin length $11.6-13.1 \% \mathrm{SL}$ in males and $11.5-13.0 \% \mathrm{SL}$ in females, 


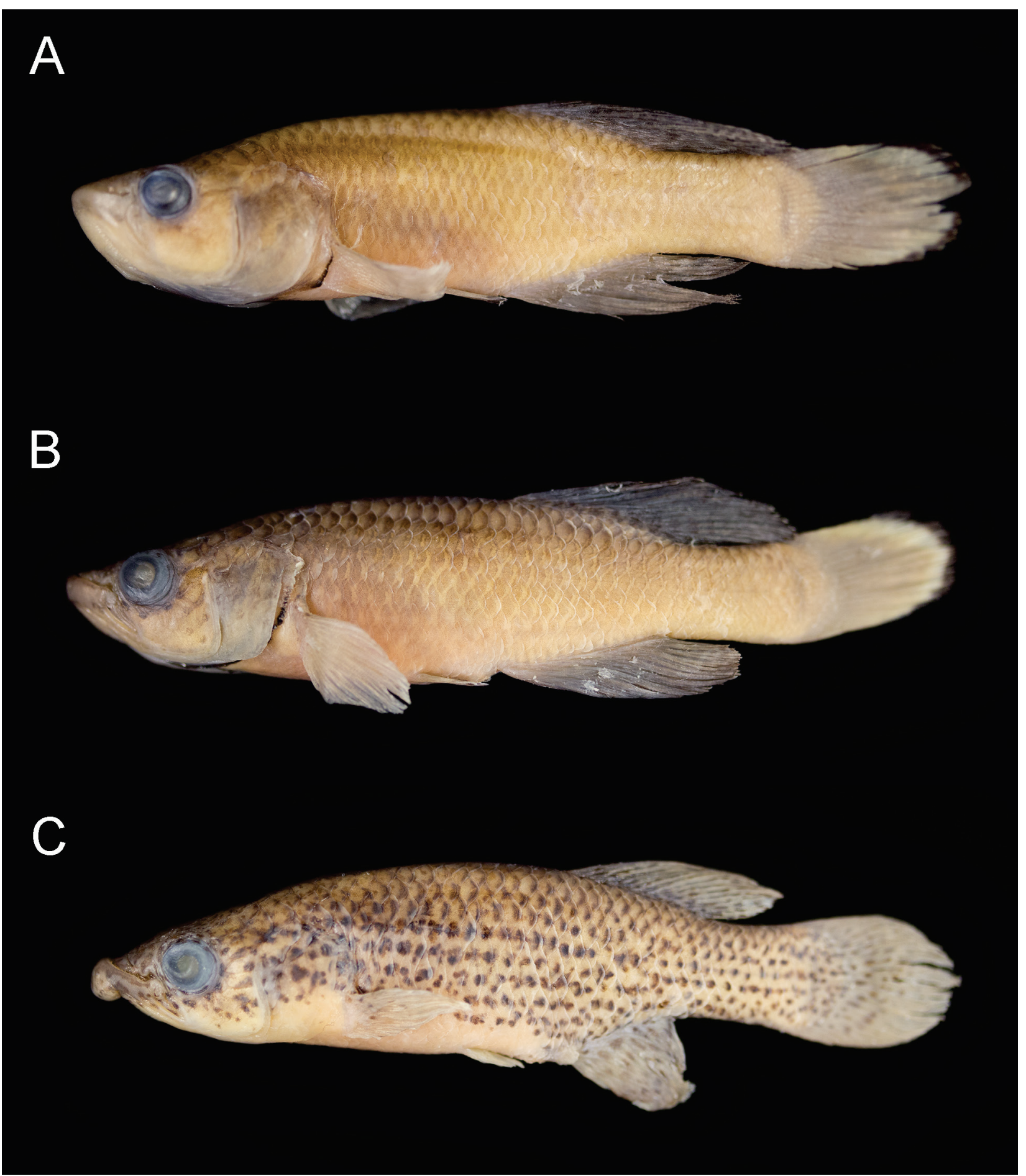

Figure 1. Nothobranchius lucius: A. MRAC A7-02-P-9, holotype, male, $49.6 \mathrm{~mm}$ SL; Tanzania: $2 \mathrm{~km} \mathrm{~S}$ of Ifakara; B. MRAC A702-P-26-27, male, 59.4 mm SL; Tanzania: 1 km S of Minepa; C. MRAC A7-02-P-26-27, female, 55.8 mm SL; Tanzania: 1 km S of Minepa.

vs. 8.6-11.0\% SL and 9.6-11.0\% SL, respectively); and two neuromasts in the posterior section of the anterior supraorbital series (vs. three).

Description. Morphometric data appear in Table 1. Dorsal profile slightly concave to nearly straight on head, convex from nape to posterior end of dorsal-fin base, about straight on caudal peduncle; ventral profile convex from lower jaw to anal-fin base, about straight on caudal peduncle. Body deep, compressed. Greatest body depth at vertical between bases of pectoral and pelvic fins. Jaws short, snout blunt in lateral view. Jaw teeth canine, numerous, irregularly arranged, outer teeth greater than internal teeth. Gill-rakers of first branchial arch $4+14-15$. Six branchiostegal rays.

Dorsal and anal fins moderate in males, extremity rounded, with short filamentous rays along distal margin, 


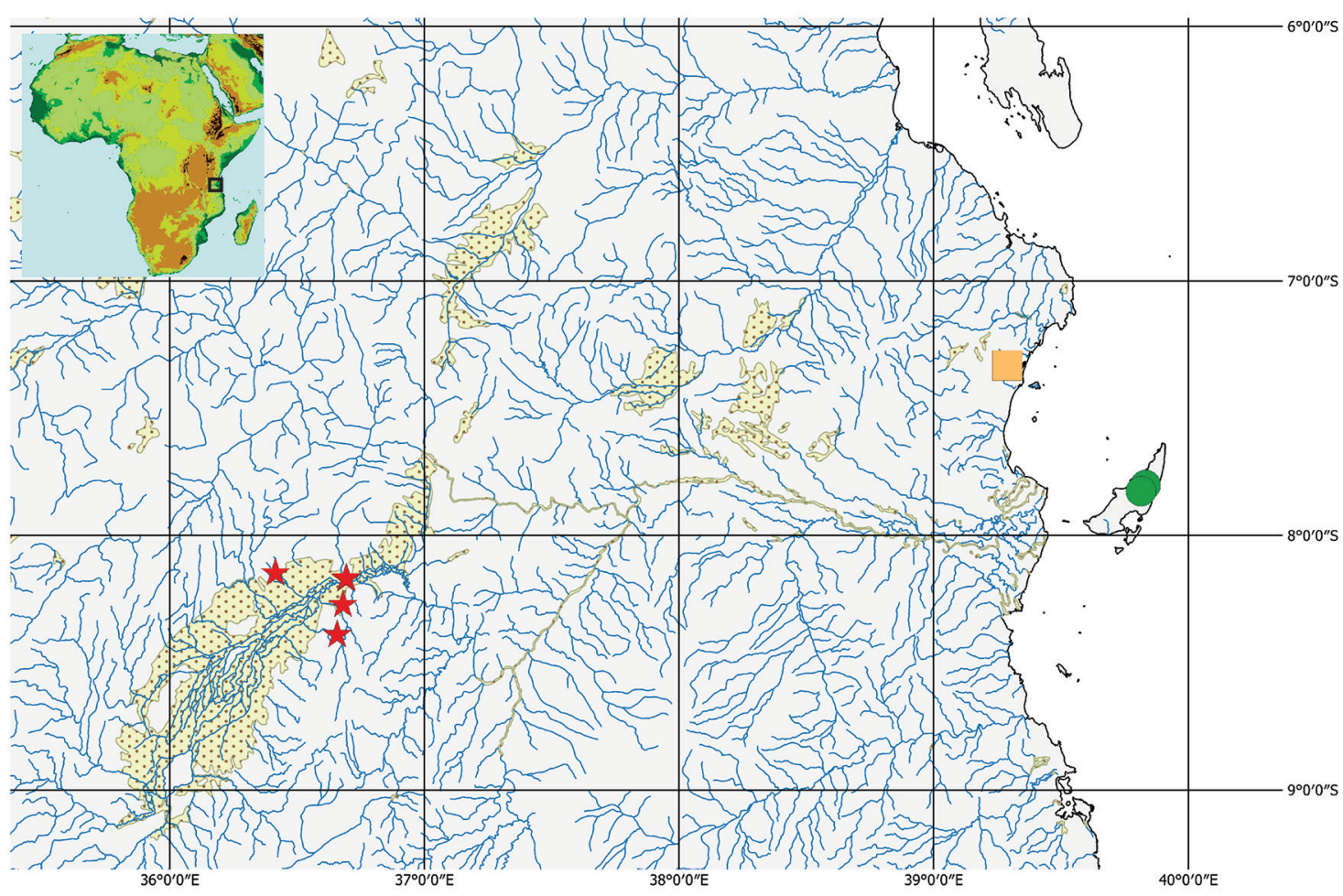

Figure 2. Geographical distribution of Nothobranchius lucius (stars), Nothobranchius cf. lucius (square), and Nothobranchius insularis sp. n. (circles); dotted areas are marshes.

Table 1. Morphometric data of Nothobranchius lucius.

\begin{tabular}{l|c|c|c}
\hline & Holotype & \multicolumn{2}{|c}{ paratypes } \\
\cline { 2 - 4 } & male & males (7) & females (9) \\
\hline Standard length (mm) & 49.6 & $40.4-53.7$ & $35.7-52.4$ \\
\hline Percent of standard length \\
\hline Body depth & 27.4 & $27.0-31.8$ & $24.6-29.6$ \\
\hline Caudal peduncle depth & 14.9 & $13.8-16.0$ & $12.4-13.9$ \\
\hline Pre-dorsal length & 61.3 & $59.9-68.7$ & $62.6-66.4$ \\
\hline Pre-pelvic length & 53.3 & $50.6-54.4$ & $50.7-56.4$ \\
\hline Length of dorsal-fin base & 25.1 & $23.2-25.9$ & $18.4-22.9$ \\
\hline Length of anal-fin base & 23.2 & $22.2-25.5$ & $15.9-18.5$ \\
\hline Caudal-fin length & 31.2 & $31.7-34.9$ & $30.3-32.9$ \\
\hline Pectoral-fin length & 22.3 & $22.2-24.5$ & $20.2-24.6$ \\
\hline Pelvic-fin length & 12.0 & $11.6-13.1$ & $11.5-13.0$ \\
\hline Head length & 33.0 & $31.8-34.6$ & $31.9-34.9$ \\
\hline Percent of head length & & \\
\hline Head depth & 78.4 & $72.7-84.8$ & $65.7-75.7$ \\
\hline Head width & 66.7 & $64.6-70.4$ & $62.5-68.3$ \\
\hline Snout length & 35.0 & $32.5-37.1$ & $30.7-33.9$ \\
\hline Lower jaw length & 30.9 & $30.2-33.6$ & $28.2-30.4$ \\
\hline Eye diameter & 23.1 & $22.7-26.2$ & $23.0-27.0$ \\
\hline
\end{tabular}

dorsal fin longer than anal fin; in females, dorsal fin rounded, anal fin sub-triangular and slightly longer than dorsal fin. Caudal fin subtruncate. Pectoral fin rounded, posterior extremity between pelvic-fin base and anus. Pelvic fin small, tip reaching urogenital papilla; pelvic-fin bases medially in contact. Dorsal-fin origin on vertical between base of first and second anal-fin rays. Dorsal-fin rays 14
16; anal-fin rays 16-18; caudal-fin rays 29-31; pectoral-fin rays $19-20$; pelvic-fin rays 6 . Minute contact organs on first and second pectoral-fin rays and distal portion of dorsal fin in males; rows of papillate contact organs along two distal thirds of most rays of anal fin in males.

Scales small, cycloid; body and head entirely scaled, except ventral surface of head. Minute filamentous contact organs along posterior margin of scales on middle portion of flank and latero-ventral portion of head in males. Body squamation extending over anterior $30 \%$ of caudal-fin base; no scales on dorsal and anal-fin bases. Frontal squamation irregularly arranged in two longitudinal rows. Longitudinal series of scales 29-30; transverse series of scales 9-11; scale rows around caudal peduncle 16.

Anterior supraorbital series of neuromasts arranged in single section placed in shallow depression, with five neuromasts; in specimens above $45 \mathrm{~mm} \mathrm{SL}$, anterior series partially divided in two sections, with two larger neuromasts in each section and smaller one between them. Posterior supraorbital series with four neuromasts placed in shallow depression. Infraorbital series with 16-17 neuromasts, pre-opercular series 12-13, mandibular 10-13. One neuromast per scale of lateral line.

Colouration in alcohol (Fig. 1). Males. Flank, dorsum and head light brown, darker on posterior portion of scales of dorsal portion of flank, dorsum and opercle; venter pinkish grey; pale grey spots on suborbital region; branchiostegal membrane dark grey. Dorsal and anal fins hyaline with transverse series of grey spots, almost inconspicuous 
in anal fin. Caudal fin pale yellow with broad dark grey to black stripe along whole fin margin, broader on posterior margin; posterior sub-marginal area lighter. Pectoral fin hyaline, pelvic fin greyish hyaline with black tip.

Females. Flank and dorsum pale brown, side of head and venter pale yellow; rounded dark brown to black dots highly concentrated on whole trunk and head except venter, irregularly arranged in horizontal rows on flank. Whole unpaired fins hyaline with dark grey dots. Paired fins hyaline; few dark grey dots on basal portion of pectoral fin.

Distribution. Nothobranchius lucius occurs in localities along the Kilombero Valley, which is limited to west by the Udzungwa Mountains and to east by the Mbarika Mountains, forming the Kibasira Swamp that is part of the Rufiji River basin (Fig. 2). This region is about $300 \mathrm{~km}$ from the coastline and collecting localities are situated at between 250 and $300 \mathrm{~m}$ asl. Two specimens collected in the Luhule River floodplains, in coastal Tanzania (MRAC A7-02-P-35-36, one male and one female, $7^{\circ} 19.95^{\prime} \mathrm{S} 39^{\circ} 17.38^{\prime} \mathrm{E}$, at about $20 \mathrm{~m}$ asl) are here tentatively identified as $N$. lucius. This species has been also recorded from the Mbezi and Ruhoi river basins, eastern Tanzanian (Wildekamp et al. 2009), but no specimen was deposited in museum collections, making identity of these records still uncertain.

\section{Nothobranchius insularis sp. n.}

http://zoobank.org/CC856CE9-244D-4642-9727-C41B819B28E7 Fig. 3, Table 2

Holotype. MRAC A7-02-P-33, 1 male, 52.9 SL; Tanzania: Mafia Island, approximately $3 \mathrm{~km}$ south of Kirongwe, $7^{\circ} 49.58^{\prime} \mathrm{S} 39^{\circ} 48.87^{\prime} \mathrm{E}$, about $15 \mathrm{~m}$ asl; B. Watters et al., 31 May 2002.

Paratypes. MRAC A7-02-P-34, 1 female, $46.4 \mathrm{~mm}$ SL; collected with holotype. MRAC A702-P-38-44, 4 males, 43.7-55.2 mm SL (1 C\&S), 3 females, 44.0-49.8 mm SL; Tanzania: Mafia Island, approximately $0.5 \mathrm{~km}$ east of Kirongwe, $7^{\circ} 48.12^{\prime} \mathrm{S} 39^{\circ} 49.97^{\prime} \mathrm{E}$, about $10 \mathrm{~m}$ asl; same collectors and date as holotype.

Diagnosis. Nothobranchius insularis is distinguished from all species of the $N$. melanospilus group, except $N$. lucius, in possessing snout pointed in lateral view, jaws moderately long (vs. snout blunt to weakly pointed, jaws short); caudal fin, in males, with broad dark grey to black band on the posterior margin (vs. narrow); presence, in females, of dark dots over the whole flank (dark dots when present restricted to the posterior portion of the flank). The new species differs from $N$. lucius by having inner premaxillary teeth smaller than teeth of the outer premaxillary tooth row (vs. larger); caudal fin subtruncate in males (vs. rounded); in females, flank dark dots are vertically elongated and often arranged in oblique rows (vs. dots rounded, arranged in horizontal rows); unpaired fins, in females, with dark grey dots when present restricted to their basal portion (extending over most fin); caudal, pec- toral and pelvic fins shorter (caudal fin length 26.9-29.6 $\% \mathrm{SL}$ in males and 22.8-27.4\% SL in females of $N$. insularis, vs. 31.3-34.9\% SL in males and 30.3-32.9\% SL in females of $N$. lucius; pectoral-fin length 17.1-21.8\% SL in males and $14.2-19.3 \% \mathrm{SL}$ in females, vs. $22.2-24.5$ $\%$ SL and 20.2-24.6\% SL, respectively; pelvic-fin length 8.6-11.0 \% SL in males and 9.6-11.0\% SL in females, vs. $11.6-13.1 \% \mathrm{SL}$ and $11.5-13.0 \% \mathrm{SL}$, respectively); and three neuromasts in the posterior section of the anterior supraorbital series (vs. two).

Description. Morphometric data appear in Table 2. Dorsal and ventral profiles slightly convex from snout to posterior end of dorsal and anal-fin bases, about straight on caudal peduncle. Body relatively slender, compressed. Greatest body depth at vertical just in front of pelvic-fin base. Jaws slightly elongated, snout pointed in lateral view. Jaw teeth canine, numerous, irregularly arranged, outer teeth greater than internal teeth. Gill-rakers of first branchial arch 4-5+14-15. Six branchiostegal rays.

Dorsal and anal fins broad in males, extremity rounded, with short filamentous rays along distal margin, dorsal fin slightly longer than anal fin; in females, dorsal fin rounded, anal fin sub-triangular and slightly longer than dorsal fin. Caudal fin subtruncate. Pectoral fin rounded, posterior extremity between pelvic-fin base and anus. Pelvic fin small, tip reaching between anus and urogenital papilla; pelvic-fin bases medially in close proximity. Dorsal-fin origin on vertical between base of first and third anal-fin rays. Dorsal-fin rays 15-16; anal-fin rays 16-18; caudal-fin rays 29-30; pectoral-fin rays 19; pelvic-fin rays 6 . Minute contact organs on first and second pectoral-fin rays in males; rows of papillate contact organs along distal portion of middle dorsal-fin rays and two thirds of most rays of anal fin in males.

Scales small, cycloid; body and head entirely scaled, except ventral surface of head. Minute filamentous contact organs along posterior margin of scales on middle portion of flank and latero-ventral portion of head in males. Body squamation extending over anterior $40 \%$ of caudal-fin base; no scales on dorsal and anal-fin bases. Frontal squamation irregularly arranged in two longitudinal rows. Longitudinal series of scales 31-32; transverse series of scales 9-10; scale rows around caudal peduncle 16.

Anterior supraorbital series of neuromasts arranged in two separate sections, each placed in shallow depression, the anterior section with two neuromasts, the posterior one with three; sometimes minute neuromast between depressions. Posterior supraorbital series with four neuromasts placed in shallow depression. Infraorbital series with 18-21 neuromasts, pre-opercular series 14-18, mandibular 17-18. One neuromast per scale of lateral line.

Colouration in alcohol (Fig. 3). Males. Flank, dorsum and head light brown, darker on posterior portion of scales of dorsal portion of flank, dorsum and opercle; venter pinkish grey; branchiostegal membrane dark grey. Dorsal and anal fins hyaline with transverse series of grey spots, almost inconspicuous in anal fin. Caudal fin pale yellow with dark grey to black stripe along whole fin 


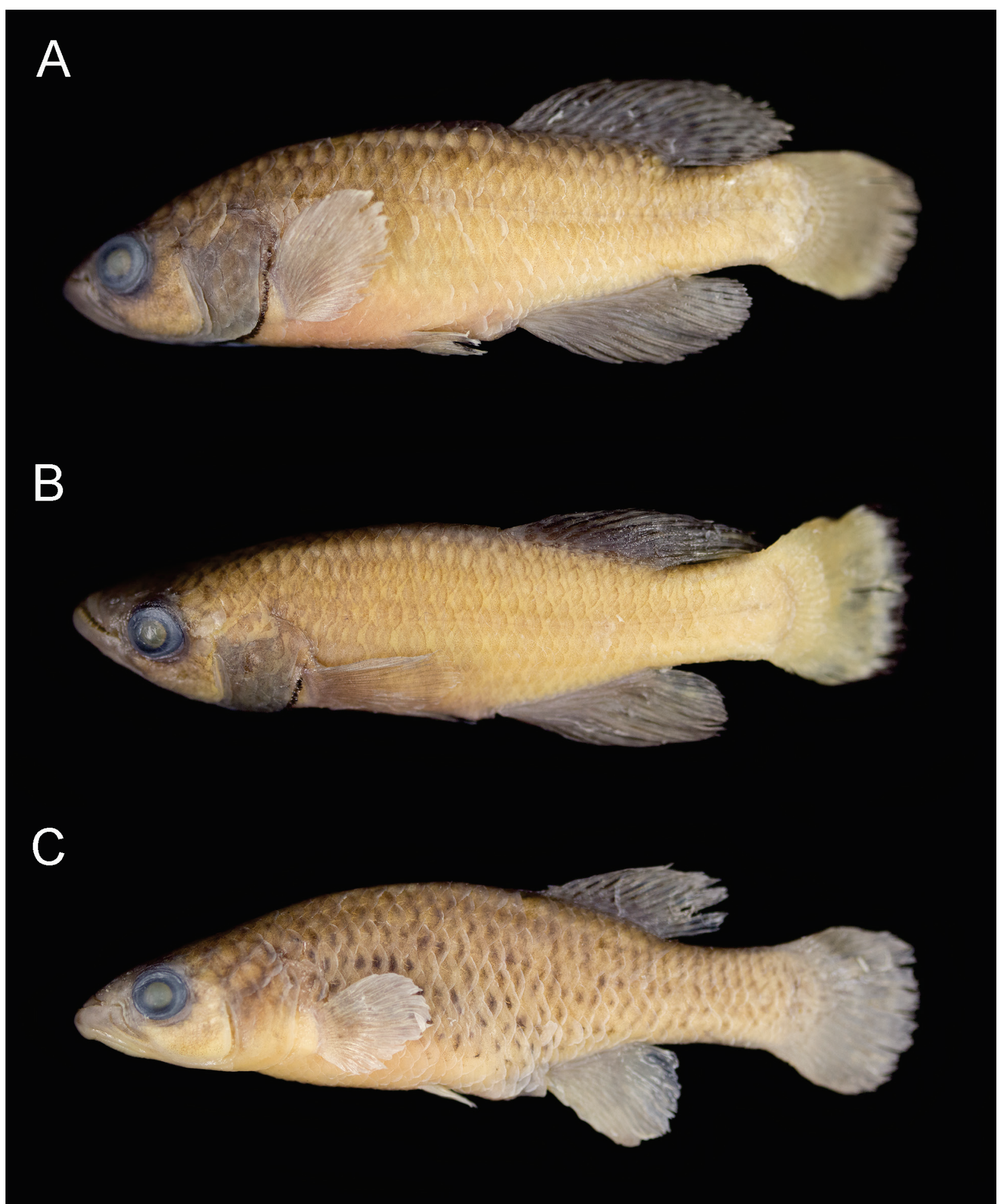

Figure 3. Nothobranchius insularis sp. n.: A. MRAC A7-02-P-33, holotype, male, 52.9 mm SL; Tanzania: 3 km S of Kirongwe, Mafia Island; B. MRAC A7-02-P-38-44, paratype, male, $48.3 \mathrm{~mm}$ SL; Tanzania: $0.5 \mathrm{~km} \mathrm{~S}$ of Kirongwe, Mafia Island; C. MRAC A7-02-P-38-44, paratype, female, $49.8 \mathrm{~mm}$ SL; Tanzania: $0.5 \mathrm{~km} \mathrm{~S}$ of Kirongwe, Mafia Island.

margin, broader on posterior margin. Pectoral fin hyaline, pelvic fin greyish hyaline with black tip.

Females. Flank and dorsum pale brown, side of head and venter pale yellow; vertically elongated dark grey to black dots irregularly arranged in oblique rows on whole flank; sometimes few pale grey dots on opercular region. Unpaired fins hyaline; elongated grey dots on basal portion of dorsal fin; anal and caudal fin often without dark marks, sometimes with almost inconspicuous pale grey dots on basal portion. Paired fins hyaline. 
Table 2. Morphometric data of Nothobranchius insularis.

\begin{tabular}{l|c|c|c}
\hline \multirow{2}{*}{} & Holotype & \multicolumn{2}{|c}{ paratypes } \\
\cline { 2 - 4 } & male & males (3) & females (4) \\
\hline Standard length $(\mathrm{mm})$ & 52.9 & $37.4-46.1$ & $44.0-49.8$ \\
\hline Percent of standard length \\
\hline Body depth & 30.9 & $29.7-30.4$ & $26.4-29.9$ \\
\hline Caudal peduncle depth & 15.0 & $13.6-14.8$ & $13.3-14.1$ \\
\hline Pre-dorsal length & 63.5 & $59.9-65.2$ & $64.7-66.7$ \\
\hline Pre-pelvic length & 51.4 & $48.5-51.1$ & $50.7-52.0$ \\
\hline Length of dorsal-fin base & 24.7 & $20.5-25.4$ & $19.1-21.5$ \\
\hline Length of anal-fin base & 23.0 & $20.1-24.0$ & $15.1-16.9$ \\
\hline Caudal-fin length & 27.1 & $26.9-29.6$ & $22.8-27.4$ \\
\hline Pectoral-fin length & 18.5 & $17.1-21.8$ & $14.2-19.3$ \\
\hline Pelvic-fin length & 10.0 & $8.6-11.0$ & $9.6-11.0$ \\
\hline Head length & 32.1 & $31.0-32.3$ & $29.5-32.8$ \\
\hline Percent of head length & \multicolumn{3}{|l}{} \\
\hline Head depth & 85.3 & $79.3-82.7$ & $77.1-81.2$ \\
\hline Head width & 67.0 & $65.0-65.8$ & $64.6-70.1$ \\
\hline Snout length & 34.0 & $26.9-32.1$ & $32.7-37.7$ \\
\hline Lower jaw length & 33.6 & $29.7-32.8$ & $26.7-30.8$ \\
\hline Eye diameter & 26.7 & $26.7-27.9$ & $26.4-28.8$ \\
\hline
\end{tabular}

Etymology. From the Latin insularis, meaning pertaining to an island and referring to the occurrence of the new species on Mafia Island.

Distribution. Nothobranchius insularis is known from two close localities in the northern part of the Mafia Island, Tanzania, at about 10-15 m asl (Fig. 2).

\section{Discussion}

Wildekamp et al. (2009) designated the type series of $N$. lucius containing the holotype and 22 paratypes that were collected in the Kilombero River drainage. An additional 18 non-type specimens were also listed. However, the table of morphometric and meristic data included in that paper indicates a total of 53 specimens of $N$. lucius examined, not 41 as indicated above. Such discrepancy supports the idea that the number of specimens used in the description was larger than that reported in the type material list, even when adding specimens listed under the non-types section that also includes material herein described as $N$. insularis. It is remarkable to notice that the type series of $N$. lucius includes some specimens that are poorly preserved (e.g. part of MRAC A7-02-P-10-25). These latter specimens have deformed body and damaged fins. Interestingly, other non-type specimens that are listed from the same drainage are well preserved (e.g. MRAC A7-02-P-26-27, 28-32).

Herein I speculate that measurements derived from poorly preserved specimens contributes to the variation presented by Wildekamp et al. (2009), which exceeds the variation reported herein based solely on the well preserved specimens reported by these authors. In addition, I have found discrepancies in what they report for some meristic characters, which are not subject to misinterpretation due to poor preservation. For example,
Wildekamp et al. (2009) report the following for $N$. lucius: dorsal-fin rays $14-17$, anal-fin rays 15-19, longitudinal series scales 31-35, and transverse series scales 12-14. Herein, however, I document that dorsal-fin rays range from 15-17, never 14; anal-fin rays range from 16-18, never 15 nor 19 ; longitudinal series scales range from 31-33, never 34 nor 35; and transverse series scales were 9-10, never 12-14. Lower fin-ray counts reported by Wildekamp et al. (2009) may be due to the first ray being often minute and embedded by thick epithelial tissue, but other differences noted above can not be explained.

Wildekamp et al. (2009: 238) distinguished N. lucius from other morphologically similar congeners by it having a more slender body and stronger dentition. When diagnosing $N$. lucius, Wildekamp et al. (2009: 247) distinguished this species from $N$. melanospilus and $N$. makondorum by the longer head, longer snout and more slender body in males. Morphometric values presented in that study, however, were notably overlapped among the three species, indicating that these characters are not useful to effectively distinguish species of the $N$. melanospilus group. I confirm this conclusion in the present study. The present comparison of jaw dentition in species of the $N$. melanospilus group also indicates that the dentition of $N$. lucius and $N$. insularis is not stronger than in other species, but in fact, $N$. lucius and $N$. insularis differs from other species of the group by both having more elongated jaw bones, which often yields a pike-like appearance in lateral view. In $N$. lucius and $N$. insularis the length between the anterior border of the dentary and the posterior tip of the angulo-articular is longer than the length between the anterior tip of the quadrate and the posterior margin of the preopercle (Fig. 4A; vs. shorter in the remaining species of the $N$. melanospilus group, Fig. 4B).

According to Wildekamp et al. (2009: 238), N. lucius may be distinguished from other species of the $N$. melanospilus group by two colouration characters: "a denser pattern of dark brown (not black) spots on the body, head and all fins of the females" (vs. black spots on the flank and base of the unpaired fins in N. melanospilus and grey spots on the flank in N. makondorum), and "a wide black margin and orange-red submargin to the caudal fin" in males (vs. caudal fin red with a narrow black margin). However, the first diagnostic character does not correspond to the figure of a live female of $N$. lucius from the type locality that is included in that same paper. The female in the figure shows that black dots, not brown, cover the whole flank, the side of the head, and the unpaired fins (Wildekamp et al. 2009: 248, fig. 9). In preserved females of $N$. lucius here examined, dots are dark brown to black, rounded, and distributed on the whole flank, side of the head, a large portion of the unpaired fins, and the basal portion of the pectoral fin; the dots of the flank are mainly arranged in horizontal rows (Fig. 1C). The colour pattern documented here for $N$. lucius greatly differs from the colour pattern exhibited by preserved females of $N$. insularis. In this species, dark grey to black dots are vertically elongated and mainly arranged in oblique rows 

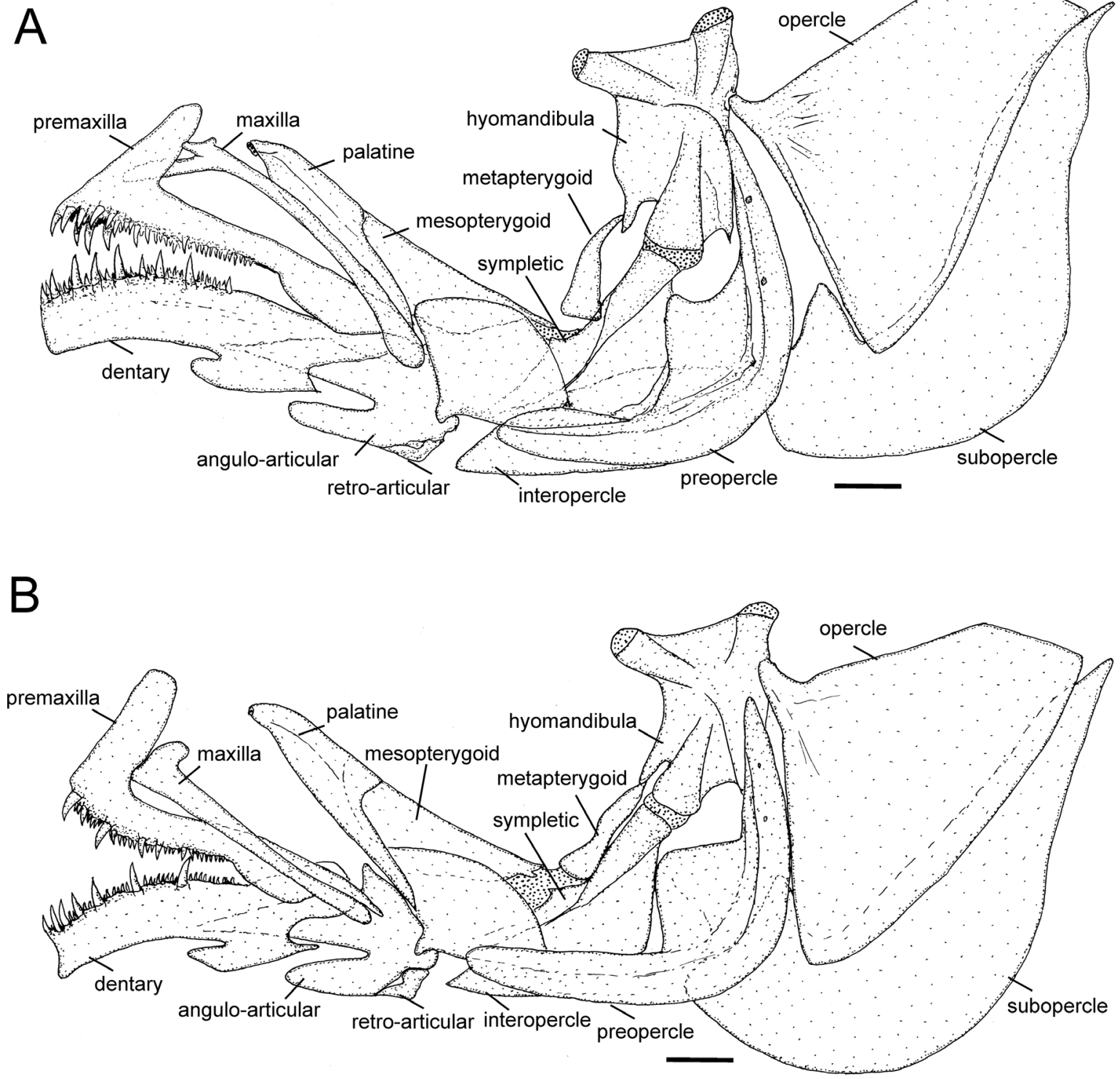

Figure 4. Jaws, jaw suspensorium and opercular apparatus, left side, lateral view, of: A. Nothobranchius lucius, paratype, male, MRAC A7-02-P-10-25, 43.0 mm SL; B. N. melanospilus, male, UFRJ 6591, 43.5 mm SL. Larger stippling indicates cartilage. Scale bar $=1 \mathrm{~mm}$.

on the flank, being rare or absent on the side of the head, and are restricted to the basal portion of the unpaired fins, while being absent on the pectoral fin (Fig. 2C). The occurrence of this female colour pattern in live exemplars of $N$. insularis is confirmed in a photograph of a live female, published in an aquarium journal paper that is a report of a collecting trip in the Mafia Island (Nagy 2009: 154).

Wildekamp et al. (2009) first diagnosed the N. melanospilus group, comprising $N$. lucius, $N$. makondorum and $N$. melanospilus, on the basis of the presence of dark dots on the flank of females. However, examination of the material listed by Wildekamp et al. (2009) as belonging to $N$. makondorum revealed that only female specimens from the type locality area (i.e., Ruvuma River basin, southern Tanzania) have grey dots on the flank, whereas specimens from all other areas to south do not show dark pigmen- tation. Although this group is corroborated by molecular data (Dorn et al. 2014), no unique morphological character was found to be useful to unambiguously diagnose the $N$. melanospilus group as delimited by Wildekamp et al. (2009). On the other hand, a more inclusive clade also comprising $N$. elongatus Wildekamp, 1982, N. hengstleri Valdesalici, 2007, $N$. insularis, $N$. interruptus Wildekamp \& Berkenkamp, 1979, N. jubbi Wildekamp \& Berkenkamp, 1979, and N. krammeri Valdesalici, 2008, in adittion to $N$. lucius, $N$. makondorum and $N$. melanospilus, is here diagnosed by the presence of two neuromasts in the anterior section of the anterior supraorbital series (Fig. 5). In other nothobranchines, the anterior section contains a single neuromast. The $N$. melanospilus group as herein delimited is also supported by molecular data (Wildekamp et al. 2009, Dorn et al. 2014). Therefore, I 

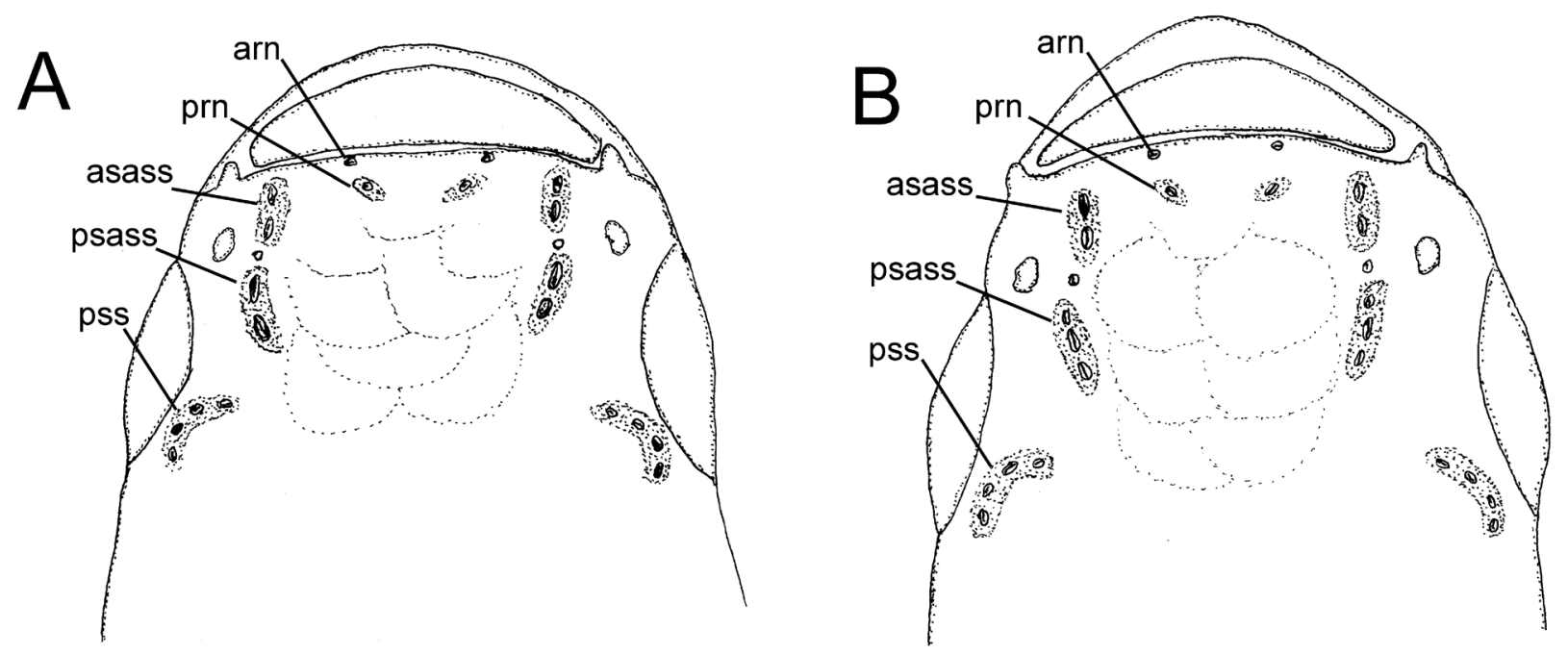

Figure 5. Diagrammatic representation of the latero-sensory system on the dorsal surface of the head in: A. Nothobranchius lucius, MRAC A7-02-P-28-32, male, 43.6 mm SL; B. Nothobranchius insularis sp. n., MRAC A702-P-38-44, paratype, male, 48.3 mm SL. arn - anterior rostral neuromast; asass - anterior section of the anterior supraorbital series; prn - posterior rostral neuromast; psass - posterior section of the anterior supraorbital series; pss - posterior supraorbital series.

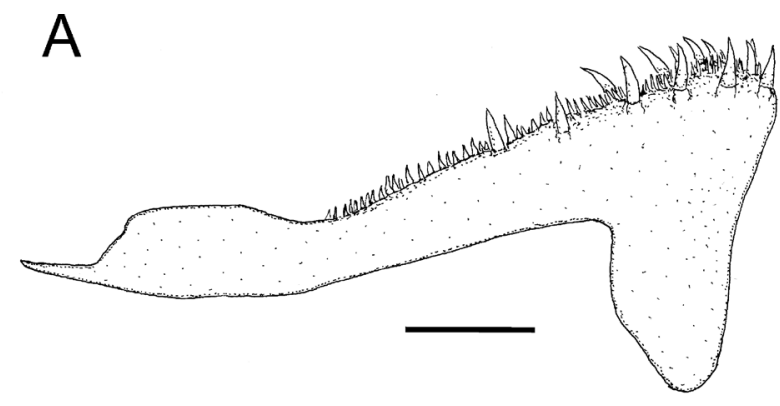

B

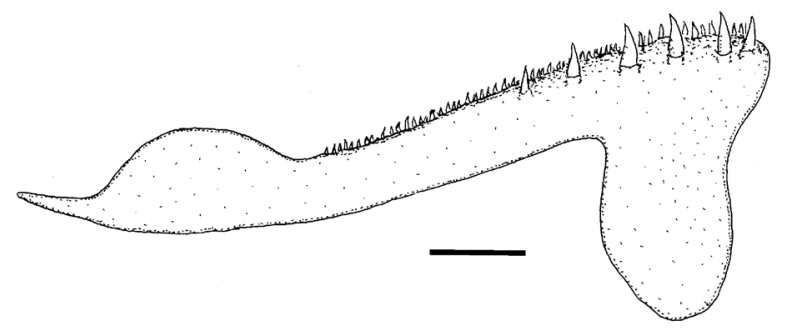

Figure 6. Left isolated premaxilla, dorsal view, ascending process inclined backwards, of: A. Nothobranchius lucius, paratype, male, MRAC A7-02-P-10-25, 43.0 mm SL. B. Nothobranchius insularis sp. n., paratype, male, MRAC A702-P-38-44, 43.7 $\mathrm{mm}$ SL. Scale bar $=1 \mathrm{~mm}$.

propose to include all the eight species listed above in the N. melanospilus group.

Monophyly of the group comprising $N$. lucius and $N$. insularis is supported by derived characters states used to distinguish them from other congeners, including the presence of dark dots on the whole flank in females and the relatively long jaws, as discussed above. The present study also indicates that two character states of the jaw suspenso- rium are uniquely found in $N$. lucius and $N$. insularis: the metapterygoid is curved and its middle and dorsal portions are separated from the sympletic by a broad interspace (vs. nearly straight and in close proximity or in contact with sympletic) and the posterior process of the quadrate is short, its length shorter than the ventral length of the quadrate without process (vs. approximately equal or greater) (Fig. 4). Among species of the N. melanospilus group, $N$. lucius is unique in having an inner row of teeth directed inside the mouth on the median portion of premaxilla that are longer than the teeth of the external row (Figs 4 and 6).

\section{Acknowledgements}

This study was developed during a six-month stay at Muséé Royal de l'Afrique Centrale, Tervuren, Belgium (MRAC), funded by $\mathrm{CNPq}$ (Conselho Nacional de Desenvolvimento Científico e Tecnológico - Ministério de Ciência e Tecnologia, Brazilian Federal Government, grant process 200627/2015-5). I am especially grateful to Jos Snoecks for providing me the necessary conditions to study African killifishes at MRAC. Thanks are also due to Miguël Parrent, Baudouin Mafuta and Emmanuel Abwe for technical assistance. The manuscript befitted from the valuable criticisms provided by Emmanuel Vreven and Thomas Philbrick, and to Peter Bartsch for editorial support.

\section{References}

Azeria ET, Sanmartín I, As S, Carlson A, Burgess N (2007) Biogeographic patterns of the East African coastal forest vertebrate fauna. Biodiversity and Conservation 16: 883-912. https://doi.org/10.1007/ s10531-006-9022-0 
Costa WJEM (1988) Sistemática e distribuição do complexo de espécies Cynolebias minimus (Cyprinodontiformes, Rivulidae), com a descrição de duas espécies novas. Revista Brasileira de Zoologia 5: 557-570. https://doi.org/10.1590/S0101-81751988000400004

Costa WJEM (2001) The neotropical annual fish genus Cynolebias (Cyprinodontiformes: Rivulidae): phylogenetic relationships, taxonomic revision and biogeography. Ichthyological Exploration of Freshwaters 12: 333-383.

Costa WJEM (2002) The neotropical seasonal fish genus Nematolebias (Cyprinodontiformes: Rivulidae: Cynolebiatinae): taxonomic revision with description of a new species. Ichthyological Exploration of Freshwaters 13: 41-52.

Costa WJEM (2009) Species delimitation among populations of the eastern Tanzanian seasonal killifish Nothobranchius korthausae (Cyprinodontiformes: Nothobranchiidae). Ichthyological Exploration of Freshwaters 20: 111-126.

Davis JI, Nixon KC (1992) Populations, genetic variation, and the delimitation of phylogenetic species. Systematic Biology 41: 421-435. https://doi.org/10.1093/sysbio/41.4.421

Dorn A, Musilová Z, Platzer M, Reichwald K, Cellerino A (2014) The strange case of East African annual fishes: aridification correlates with diversification for a savannah aquatic group? BMC Evolutionary Biology 14: 210. https://doi.org/10.1186/s12862-014-0210-3

Fitzgerald WWA (1898) Travels in the coastlands of British East Africa and the islands of Zanzibar and Pemba. Chapman \& Hall, London, 834 pp.

Genade T, Benedetti M, Terzibasi E, Roncaglia P, Valenzano DR, Cattaneo A, Cellerino A (2005) Annual fishes of the genus Nothobranchius as a model system for aging research. Aging cell 4: 223-233. https:// doi.org/10.1111/j.1474-9726.2005.00165.x

Harel I, Benayoun BA, Machado B, Singh PP, Hu C-K, Pech MF, Valenzano DR, Zhang E, Sharp SC, Artandi SE, Brunet A (2015) A platform for rapid exploration of aging and diseases in a naturally short-lived vertebrate. https://doi.org/10.1016/j.cell.2015.01.038

Hoedeman JJ (1958) The frontal scalation pattern in some groups of toothcarps (Pisces, Cyprinodontiformes). Bulletin of Aquatic Biology 1:23-28.
Myers GS (1942) Studies on South American freshwater fishes I. Stanford Ichthyological Bulletin 2: 89-114.

Myers N, Mittermeir RA, Mittermeir CG, da Fonseca GAB, Kent J (2000) Biodiversity hotspots for conservation priorities. Nature 403: 853-858. https://doi.org/10.1038/35002501

Nagy B (2009) Die Insel Mafia. DKG-Journal 41: 146-157.

Neumann W (2008) Prachtgrundkärpflinge. Supplement 9. Deutsche Killifisch Gemeinschaft, Marktheidenfeld, 128 pp.

Parenti LR (1981) A phylogenetic and biogeographic analysis of cyprinodontiform fishes (Teleostei, Atherinomorpha). Bulletin of the American Museum of Natural History 168: 335-557. http://hdl.handle.net/2246/438

Pinceel T, Vanschoenwinkel B, Deckers P, Grégoir A, Ver Eecke T, Brendonck L (2015) Early and late developmental arrest as complementary embryonic bet-hedging strategies in African killifish. Biological Journal of the Linnean Society 114: 941-948. https://oi. org/10.1111/bij.12474

Polacik M, Donner MT, Reichard M (2011) Age structure of annual Nothobranchius fishes in Mozambique: is there a hatching synchrony? Journal of Fish Biology 78: 796-809. https://doi.org/10.1111/ j.1095-8649.2010.02893.x

Seegers L (1997) Killifishes of the world, Old World killis II. Verlag ACS, Mörfelden-Walldorf, 109 pp.

Taylor WR, Van Dyke GC (1985) Revised procedures for staining and clearing small fishes and other vertebrates for bone and cartilage study. Cybium 9: 107-109. http://sfi.mnhn.fr/cybium/numeros/1985/92/01-Taylor\%5b92\%5d107-119.pdf

Wildekamp RH (2004) A world of killies: atlas of the oviparous cyprinodontiform fishes of the world, vol. 4. The American Killifish Association, Elyria, Ohio, 398 pp.

Wildekamp RH, Shidlovskiy KM, Watters BR (2009) Systematics of the Nothobranchius melanospilus species group (Cyprinodontiformes: Nothobranchiidae) with description of two new species from Tanzania and Mozambique. Ichthyological Exploration of Freshwaters 20: $237-254$. 